\title{
TUMOR OF PALATAL MINOR SALIVARY GLAND: A CASE REPORT
}

\author{
Santosh S. Garag' ${ }^{1}$, Arunkumar J. S², K. C. Prasad³, Shibani Anchan ${ }^{4}$
}

\section{HOW TO CITE THIS ARTICLE:}

Santosh S. Garag, Arunkumar J. S, K. C. Prasad, Shibani Anchan. "Tumor of Palatal Minor Salivary Gland: A Case Report". Journal of Evolution of Medical and Dental Sciences 2014; Vol. 3, Issue 21, May 26; Page: 5700-5704, DOI: $10.14260 /$ jemds/2014/2652

ABSTRACT: Pleomorphic adenoma is a commonest benign tumor of the salivary glands that has elements of both epithelial and mesenchymal tissues. It is most commonly seen in the parotid and submandibular glands. Infrequently it might present as an intraoral mass, of which hard palate is the commonest site. Hereby we report a case of pleomorphic adenoma of hard palate in a 26 years old female, who presented to ENT OPD with a mass over roof of oral cavity. Fine needle aspiration of the mass clinched the diagnosis of Pleomorphic adenoma. The mass was excised completely by transoral approach.

KEYWORDS: Salivary gland, Hard palate, Pleomorphic adenoma, Fine needle aspiration, Excision.

INTRODUCTION: Salivary gland tumors are uncommon and constitute $2-6.5 \%$ of all head and neck neoplasms. ${ }^{1}$ Minor salivary gland tumors represents $9-23 \%$ of all salivary gland tumors. ${ }^{1}$ Salivary gland tumors are a heterogeneous group of lesions, which are rare, especially those affecting the Minor salivary glands ${ }^{1}$.Pleomorphic adenoma and Mucoepidermoid carcinoma are the two commonest Minor salivary gland tumors. ${ }^{1-5}$

Pleomorphic adenoma has a remarkable degree of morphological diversity whose essential components are the epithelial and myoepithelial cells, along with the mesenchymal or stromal elements.3,5,6 Pleomorphic adenoma involves parotid gland most commonly, followed by submandibular gland and minor salivary glands of palate and buccal mucosa.3,6 Intraorally commonest site for minor salivary gland tumors is the palate. ${ }^{2,6}$

Pleomorphic adenoma seen in 30-60 years of age although it can be seen in 5-10\% of cases in less than 20 yrs. age.3,5,6 Intraoral salivary gland tumors tend to be diagnosed relatively early, possibly because of their interference in speech and mastication. ${ }^{6}$ Imaging by CT coronal is useful in determining the size and extent of the lesion, especially for those involving the palate.3,5 FNAC is the widely accepted preoperative method of diagnosis of salivary tumors as they are easily accessible. ${ }^{3}$

Treatment of palatal Pleomorphic adenoma is wide local excision, achieving clear margins by excising the involved periosteum, overlying mucosa and curettage of underlying bone, with reconstruction of the defect with local flaps. Inadequate excision leads to recurrence.3, 4 Pleomorphic adenoma is a benign tumor with tendency to recur and risk of malignant transformation, which is rare for Minor salivary gland tumors. ${ }^{3}$

CASE HISTORY: A 23 years old female patient presented to ENT OPD with a chief complaint of swelling over the roof of mouth since 6 months. It was painless, progressive and not associated with any other symptoms. On examination a single, well-defined smooth surface swelling of about 4 x 3 cms was seen over right side of hard palate extending posteriorly upto the soft palate (Fig. 1). It was non tender, firm in consistency and immobile. Mucosa over the swelling was normal. Further Examination of throat, nose, ear and neck was normal. Relevant blood investigations were done 
which were within normal limits. Provisional clinical diagnosis benign neoplasm of hard palate was made. Fine needle aspiration cytology study of the swelling confirmed it as pleomorphic adenoma. Coronal CT scan of the palate showed well defined homogeneously enhancing over-hanging soft tissue density lesion in the posterior aspect of right hard palate (Fig. 2).

Patient was taken up for surgery under general anesthesia with endotracheal intubation. Mucosa of the hard palate elevated as tongue shaped flap. The mass was excised completely and underlying periosteum stripped. The palatal mucosal flap sutured with 3-0 vicryl. Histopathological examination of the excised specimen revealed the mass to be composed of epithelial and myoepithelial elements arranged in varying patterns confirmed the diagnosis of pleomorphic adenoma (Fig. 3). The patient was followed up for one year with no signs of recurrence (Fig. 4).

DISCUSSION: Salivary gland tumors are unique because of their vast range of morphological diversity between different tumor types and sometimes within the same tumor mass itself. Parotid gland is the commonest site followed by submandibular and minor salivary glands. The propensity of malignant tumors in salivary glands depends on the site. The sublingual and minor salivary gland, are known to have a high proportion of malignant tumors.in minor salivary gland tumors Pleomorphic adenoma is commonest benign tumor and mucoepidermoid carcinoma is the most common malignant tumor. ${ }^{8}$ Salivary gland neoplasm s seen commonly in $4^{\text {th }}$ to $5^{\text {th }}$ decade of life. Females have higher incidence. Palate is the commonest site followed by upper lip and buccal mucosa for intraoral minor salivary gland tumor. ${ }^{9}$

Intraoral tumors usually present as painless mass without any associated symptoms initially. Malignant tumors can cause mechanical obstruction for swallowing. Long standing benign salivary gland tumor can undergo malignant transformation if left untreated for prolonged period. Along with Minor salivary gland tumors, Palatal abscess, Nasopalatine duct cyst, torus palatinus, fibromas, hemangiomas, neurofibromas, odontogenic abscesses, myoepithelioma, lymphoma, squamous cell carcinoma and Kaposi's sarcoma should be considered in differential diagnosis for any palatal mass. ${ }^{11,12}$

The role of ENT and Oral Surgeon in early diagnosis is important as malignant salivary gland tumors can present without any specific symptoms and also early diagnosis of benign tumors can improve their prognosis by preventing its malignant transformation. ${ }^{12,13}$ Fine Needle Aspiration of mass helps in establishing the definitive diagnosis. ${ }^{14}$ Erosion of palatal bone, which is a feature of malignancy, is detected by CT scan. ${ }^{15}$ Cases of pleomorphic adenoma of palate should be treated by wide local excision along with removal of underlying periosteum, to limit the chances of recurrence. ${ }^{14}$

Simple enucleation of the swelling is associated with higher recurrence rate.

CONCLUSION: Palatal swelling has wide array of differential diagnosis, ranging from palatal abscess to mucoepidermoid carcinoma, with most of them having similar mode of presentation. Benign tumors of minor salivary gland are known to undergo malignant transformation. Early diagnosis and treatment improves overall prognosis for these patient's. Fine needle aspiration plays an important role in early diagnosis of these swellings. Complete excision of swelling with free margin is essential to avoid chances of recurrence. 


\section{REFERENCES:}

1. Fabio $\mathrm{R}$ P, Gordon A P, Oslei P A, Sow Y C. Intraoral minor salivary gland tumors: A clinicopathological study of 546 cases. Oral Oncology 2007; 43:463-70.

2. Toida $\mathrm{M}$, Shimokawa $\mathrm{K}$, Makita $\mathrm{H}$ et al. Intraoral minor salivary gland tumors: $\mathrm{A}$ clinicopathological study of 82.Int J Oral Maxillofac. Surg 2005; 34:528-32.

3. Honghai F, Jun W, Lizhen W, Zhiyuan Z, Yue H. Pleomorphic adenoma of the salivary glands in children and adolescents. Journal of paediatric surgery 2012; 47:715-19.

4. Chidzonga M M, Lopez V M, Portilla A L, Avilla C. Pleomorphic adenoma of the salivary glands: Clinicopathological study of 206 cases in Zimbabwe, Oral Surg Oral Med Oral Pathol Oral Radiol Endod 1995; 79: 747-49.

5. Jorge J, Pires F R, Alves F A et al. Juvenile Intraoral Pleomorphic adenoma: report of five cases and review of literature. Int J Oral Maxillofac Surg 2002; 31: 273-75.

6. Chau M N, Radden B G. A clinicopathological study of 53 Intraoral Pleomorphic adenomas. Int J Oral Maxillofac Surg 1989 Jun; 18 (3):158-62.

7. Tian Z, Li L, Wang L, Hu Y, Li J. Salivary gland Neoplasm's in oral and maxillofacial regions: a 23 year retrospective study of 6082 cases in an eastern Chinese population. Int J Oral Maxillofac Surg 2010 Mar;39(3):235-42

8. Dhanuthai K, Boonadulyarat M, Jaengjongdee T, Jiruedee K. A clinicopathological study of 311 Intraoral Salivary gland tumors in Thais. J Oral Pathol Med 2009 Jul; 38(6):495-500.

9. Waldron CA, Mofty SK, Gnepp DR. Tumors of the intraoral minor salivary glands: a demographic and histologic study of 426 cases. Oral Surg Oral Med Oral Pathol 1988 Sep; 66(3):323-33

10. Pinar S, Peruze C. Palatal Abscess in a Pediatric Patient: Report of a Case.European Journal of Dentistry 2008 Oct; 2: 291-93

11. Jaber MA. Intraoral minor salivary gland tumors: a review of 75 cases in a Libyan population. Int J Oral Maxillofac Surg. 2006 Feb; 35(2):150-4.

12. Nanda KS, Mohan NR, Rajashekhar DG. Pleomorphic adenoma palate: Major tumor in a minor gland. Annals of Maxillofacial Surgery 2013 Jul-Dec; 3(2): 195-97.

13. Pallagatti S, Sheikh S, Gupta D, Das A, Singh R. Carcinoma ex pleomorphic adenoma. Case report. N Y State Dent J. 2013 Jun-Jul; 79(4):52-4.

14. Mubeen K, Vijayalakshmi KR, Abhishek RP, Girish B. Giraddi, Chandravir S. Benign pleomorphic adenoma of minor salivary gland of palate. Journal of Dentistry and Oral Hygiene 2011 June; 3(6), pp. 82-88.

15. Sami PM, Fahad AS, Sam JD. Rapidly progressing palatal pleomorphic adenoma in an adolescent. International Journal of Pediatric Otorhinolaryngology 2010; 5:141-43. 


\section{CASE REPORT}

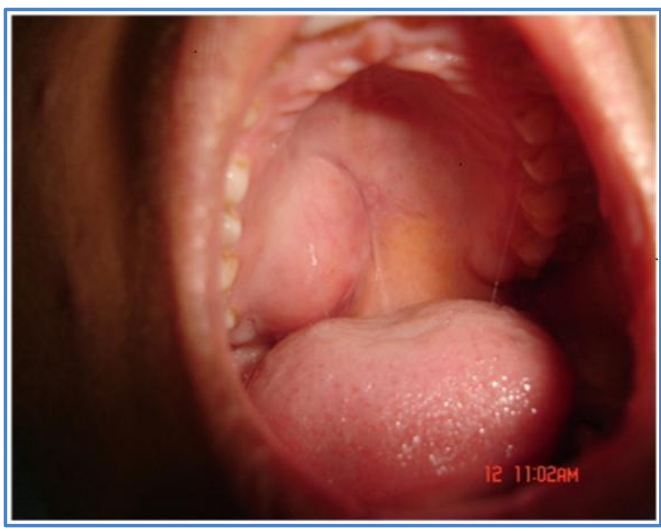

Fig. 1: Picture of the swelling on the RT. side of Palate extending onto the hard palate

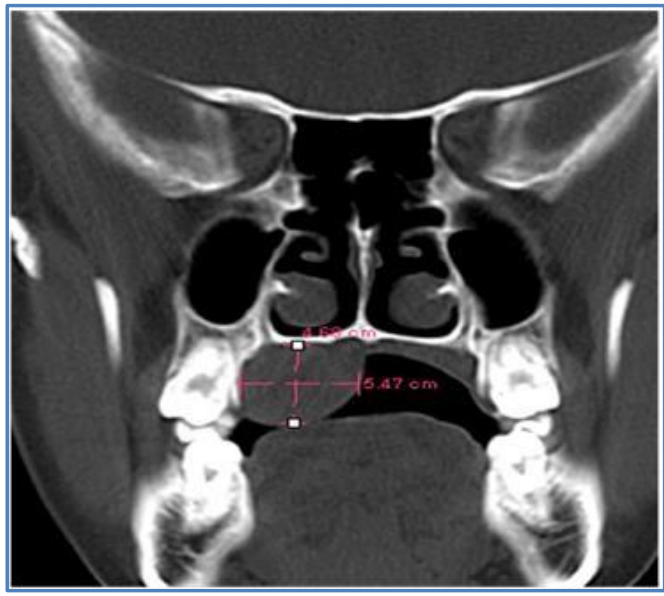

Fig. 2: CT scan picture showing vertical extent of swelling with intact underlying palatal bone

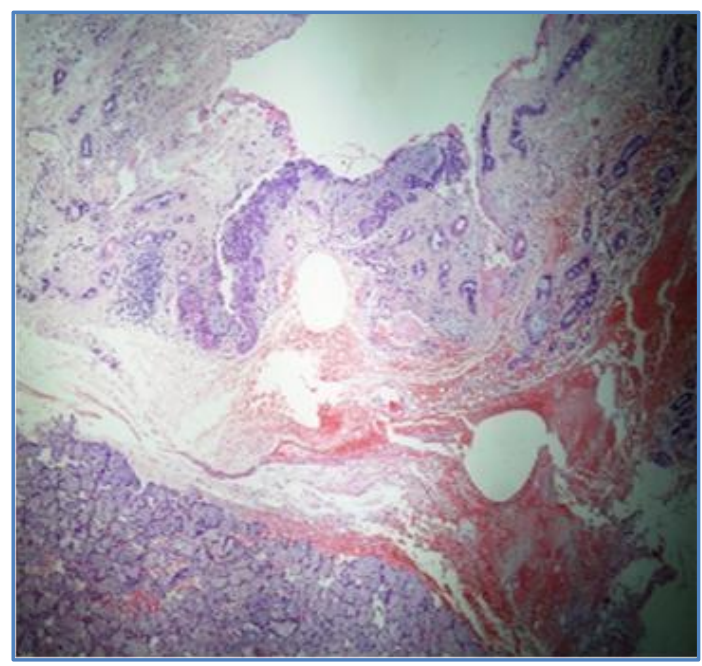

Fig. 3: Histological picture of the biopsy specimen, showing the characteristic varying patterns of epithelial and myoepithelial elements. (40x, H \& E) 


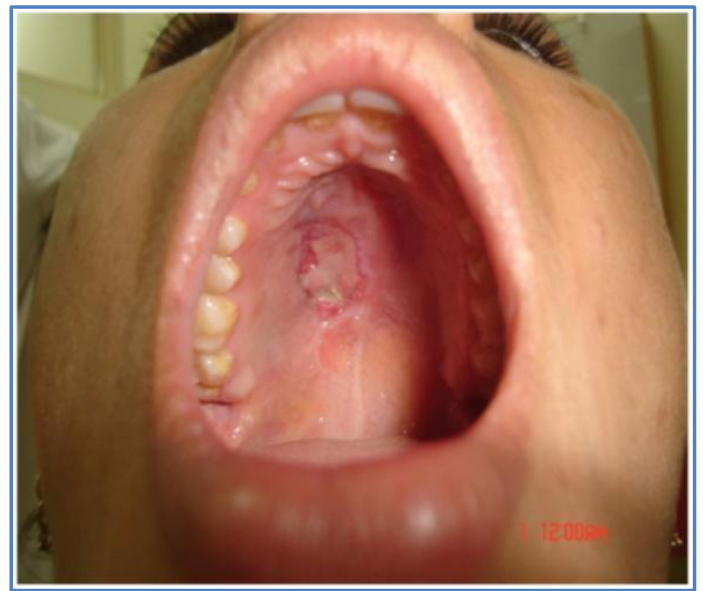

Fig. 4: Picture of the operative site, 1 month after surgery

\section{AUTHORS:}

1. Santosh S. Garag

2. Arunkumar J.S.

3. K. C. Prasad

4. Shibani Anchan

\section{PARTICULARS OF CONTRIBUTORS:}

1. Assistant Professor, Department of ENT, SDM College of Medical Sciences and Hospital, Sattur, Dharwad, Karnataka, India.

2. Professor, Department of ENT, SDM College of Medical Sciences and Hospital, Sattur, Dharwad, Karnataka, India.

3. Professor, Department of ENT, SDM College of Medical Sciences and Hospital, Sattur, Dharwad, Karnataka, India.

4. Assistant Professor, Department of ENT, SDM College of Medical Sciences and Hospital, Sattur, Dharwad, Karnataka, India.

\section{NAME ADDRESS EMAIL ID OF THE CORRESPONDING AUTHOR:}

Dr. Santosh S. Garag,

Assistant Professor,

Department of ENT,

Sri Dharmasthala Manjunatheshwara

College of Medical Sciences \& Hospital

(SDMCMS \& H),

Sattur, Dharwad-580009.

Email: santu53@gmail.com

Date of Submission: 05/05/2014.

Date of Peer Review: 06/05/2014.

Date of Acceptance: 16/05/2014.

Date of Publishing: 22/05/2014. 